\title{
Association of mortality with age of blood transfused in septic ICU patients
}

F. Robert Purdy MSc DVM MD FRCPC, Martin G. Tweeddale PhD MD FRCPC, Pamela M. Merrick BSN

Purpose: To determine, retrospectively, the age of packed red blood cell (PRBC) units transfused to patients admitted to the ICU with the diagnosis of severe sepsis and to correlate this variable with outcome.

Methods: All patients admitted to the ICU during 1992 with a diagnosis of severe sepsis were selected retrospectively. The criteria for the diagnosis of severe sepsis and septic shock were based on established guidelines. For each patient the total number of PRBC units transfused, the number of units transfused before, during and after the septic episode, and the age of each PRBC unit transfused were recorded.

Results: Of the 31 patients admitted to the ICU with severe sepsis, 19 died and 12 survived. No statistical differences between survivors and nonsurvivors were found with respect to age, sex, number of days in ICU, duration of sepsis, incidence of septic shock, admission Apache II score or total number of PRBC units transfused. During sepsis the median age of PRBC units transfused to survivors was 17 days (range 5-35) vs 25 days (range 9-36) for nonsurvivors $(P<0.000 \mathrm{I})$. A negative correlation $(r=-0.73)$ was found between the proportion of PRBC units of a given age transfused to survivors and increasing age of PRBC.

Conclusion: This is the first study to report a correlation of mortality with the age of PRBC transfused. The cause of this association is unclear. If this association is confirmed by a prospective randomised trial it would have major implications for the use of PRBC in severe sepsis.

Objectif : Déterminer rétrospectivement l'âge des concentrés érythrocytaires (CE) transfusés à des patients admis à l'unité des soins intensifs (USI) avec un diagnostic de sepsis grave et vérifier si cette variable a une corrélation avec le devenir des patients.

Méthodes : Tous les patients admis à l'USI en 1992 avec un diagnostic de sepsis grave ont fait l'objet de cette recherche rétrospective. Les signes et symptômes usuels ont servi à établir les critères de sepsis grave et de choc septique. Pour chacun des patients la quantité totale des CE transfusés, le nombre de CE transfusés avant, pendant et après l'épisode septique et l'âge de chaque CE transfusé ont été enregistrés.

Résultats : Parmi les 31 patients admis à I'USI pour sepsis grave, 19 sont décédés et 12 ont survécu. II n'y avait pas de différence statistique entre survivants et non survivants en rapport à l'àge, le sexe, la durée du séjour à I'USI, la durée du sepsis, l'incidence du choc septique, le score APACHE II à l'admission et le nombre de CE transfusés. Au cours du sepsis, l'âge médian des CE transfusés était de 17 jours (écart $5-35$ ) vs 25 jours (écart 9-39) pour les non survivants $(P<0,000 \mathrm{I})$. On a trouvé une corrélation négative $(r=-0,73)$ entre la proportion de CE d'un âge déterminé transfusé aux survivants et l'accroissement de l'âge des CE.

Conclusion : II s'agit ici de la première étude concluant à une corrélation avec l'âge des CE transfusés. La raison de cette association n'est pas claire. Si une étude aléatoire prospective parvient à confirmer cette assertion, elle aurait des répercussions majeures sur la transfusion de CE dans le sepsis grave.

From the Intensive Care Unit and Department of Anaesthesia, Vancouver Hospital and Health Sciences Centre, Vancouver, BC, Canada. Address correspondence to: M.G. Tweeddale MD, Intensive Care Unit, Vancouver Hospital and Health Sciences Centre, 855 West 12 th Ave., Vancouver, B.C. Canada V5Z IM9.

This study was presented, in part, as a poster at the combined meeting of the British and Irish Intensive Care Societies, Dublin Ireland, April 1994 and at the Canadian Critical Care Society meeting, Toronto, September 1994.

Accepted for publication September 10, 1997. 


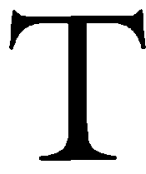

HERE are no reports correlating clinical outcome with the age of packed red blood cells (PRBC) transfused in critically ill patients. The currently accepted limit of 35 days for PRBC storage was derived from in vitro rheological and metabolic indices and post-transfusion erythrocyte survival percentages. ${ }^{1}$ Clinical trials to support this limit have not been performed. Increased rates of infection, multi-organ dysfunction syndrome and mortality have been associated with PRBC transfusion in critically ill patients, ${ }^{2,3}$ but immunological mechanisms were postulated as the likely cause and the age of the PRBC units was not considered. These studies have been controversial in that PRBC transfusion may be a marker for severity of illr 'ss and not an independent predictor of outcome. However, there are two studies suggesting that the age of blood transfused to critically ill patients may influence the physiological response to transfusion ${ }^{4}$ and the clinical outcome. ${ }^{5}$

The changes that occur with storage of red blood cells are well documented and include both reversible and irreversible alterations. ${ }^{1}$ These changes include decreased levels of 2,3-DPG and altered red blood cell rheology both of which may adversely affect oxygen delivery to, and oxygen uptake by, tissues. Though it is not common practice, it has been recommended (based on 2,3-DPG depletion studies) that patients with a compromised circulation should not receive PRBC units older than 14 days. ${ }^{1}$ We hypothesised that mortality might be influenced by the transfusion of older PRBC in septic ICU patients. Therefore, we determined, retrospectively, the age of PRBC transfused in a group of septic ICU patients and determined its relationship to survival.

\section{Methods}

All patients admitted to the ICU during the calendar year 1992 with a diagnosis of severe sepsis were selected retrospectively from the data base of our tertiary care, multidisciplinary, adult ICU. Study design was approved by the UBC Clinical Screening Committee for Research Involving Human Subjects. Patients developing severe sepsis after ICU admission could not be included since the ICU data base recorded only the admission diagnosis. The criteria for the diagnosis of severe sepsis and septic shock were based on established guidelines ${ }^{6}$ (Table I). The earliest time at which the criteria for sepsis were met was identified from each record and was considered to be the onset of the septic episode. Resolution of sepsis was defined arbitrarily and prospectively as at least $48 \mathrm{hr}$ of failure to meet the criteria for sepsis. Infection was confirmed by the finding of a clinically appropriate culture-positive site of infec- tion. Outcome was determined on discharge from the ICU. For each patient the following data were recorded: age, sex, outcome, number of days in hospital, number of days in ICU, admission APACHE II score, admission diagnosis, focus of infection, organism(s) cultured, duration of sepsis, inotrope use, total number of PRBC units transfused, the number of units transfused before, during and after the septic episode, and the age of each PRBC unit transfused. The storage medium for all PRBC was CPDA-1. Indications for transfusion were based on the clinical judgment of the ICU attending physician.

Group differences were analysed by Mann-Whitney tests while proportional data were compared using chi-square tests or Fisher's exact tests as appropriate. Linear regression analysis was performed on the proportion of PRBC units of a given age transfused to survivors. Differences were considered significant at $P<0.05$. Bonferroni's correction was applied when appropriate to adjust for multiple comparisons. Because data were not normally distributed, results are reported as medians and range.

\section{TABLE I Definitions}

\section{1) Definitions from the American College of Chest \\ Physicians/Society of Critical Care Medicine Consensus \\ Conference on sepsis and organ failure 1992.6}

Sepsis: The systemic response to infection. This systemic response is manifested by two or more of the following conditions as a result of infection:

Temperature $>38^{\circ} \mathrm{C}$ or $<36^{\circ} \mathrm{C}$

Heart rate $>90 \mathrm{bpm}$

Respiratory rate $>20$ breaths $\cdot \mathrm{min}^{-1}$ or $\mathrm{PaCO}_{2}<3 \mathrm{mmHg}(<4.3 \mathrm{kPa})$ WBC $>12,000$ cells $\cdot \mathrm{mm}^{-3},<4000$ cells $\cdot \mathrm{mm}^{-3}$ or $>10 \%$ immature (band) forms

Severe Sepsis: Sepsis associated with organ dysfunction, hypoperfu sion, or hypotension. Hypoperfusion and perfusion abnormalities may include, but are not limited to lactic acidosis, oliguria, or an acute alteration in mental status.

Septic Shock: Sepsis with hyporension, despite adequare fluid resuscitation, along with the presence of perfusion abnormalitics that may include, but are not limited to, lactic acidosis, oliguria, or an acute alteration in mental status. Patients who are on inotropic or vasopressor agents may not be hypotensive at the time that perfusion abnormalities are measured.

Hypotension: A systolic BP of $<90 \mathrm{~mm} \mathrm{Hg}$ or a reduction of $>40$ $\mathrm{mmHg}$ from baseline in the absence of other causes for hypotension. Multiple Organ Dyfunction Syndrome: Presence of altered organ function in an acutely ill patient such that homeostasis cannot be maintained without intervention.

\section{2) Definitions made for this study.}

Onset of Sepsis: The time when the criteria for sepsis are first met. Resolution of Sepsis: The time when the criteria for sepsis are absent for 48 consecutive hours. 
TABLE II Clinical characteristics of 31 adult patients admitted to ICU with severe sepsis.

\begin{tabular}{llllll}
\hline & $\begin{array}{l}\text { Age } \\
(\mathrm{yr})\end{array}$ & $\begin{array}{l}\text { Sex } \\
(\mathrm{male} / \mathrm{female})\end{array}$ & APACHE II Score* & $\begin{array}{l}\text { Number with septic } \\
\text { shock }\end{array}$ & Days in ICU* $^{\star}$ \\
\hline $\begin{array}{l}\text { Survivors } \\
(\mathrm{n}=12)\end{array}$ & $66(19-84)$ & $7 / 5$ & $31(18-45)$ & 9 & $5(2-104)$ \\
$\begin{array}{l}\text { Nonsurvivors } \\
(\mathrm{n}=19)\end{array}$ & $61(16-81)$ & $10 / 9$ & $33(20-55)$ & 16 & $4(1-216)$ \\
$P$ & 0.56 & 0.76 & 0.06 & 0.65 & .27 \\
\hline
\end{tabular}

*median(range)

TABLE III Number and age of PRBC units transfused to septic patients.

\begin{tabular}{|c|c|c|c|c|}
\hline & \multicolumn{2}{|c|}{ During Hospital Admission } & \multicolumn{2}{|c|}{ During Septic Episode* } \\
\hline & $\begin{array}{l}\text { Number of units } \\
\text { transfused/patient }\end{array}$ & $\begin{array}{l}\text { Age of units } \\
\text { (days) }\end{array}$ & $\begin{array}{l}\text { Number of units } \\
\text { transfused/patient }\end{array}$ & $\begin{array}{l}\text { Age of units } \\
\text { (days) }\end{array}$ \\
\hline survivors & $6(1-98)$ & $21(5-35)[18-23]$ & $5(2-70)$ & $17(5-35)[16-19]$ \\
\hline nonsurvivors & $10(2-103)$ & $24(7-36)[23-26]$ & $8(2-103)$ & $25(9-36)[23-27]$ \\
\hline$P$ & 0.21 & $<0.0001$ & 0.21 & $<0.0001$ \\
\hline
\end{tabular}

Values are median(range) $[95 \% \mathrm{CI}]$

"results do not include two survivors who did not receive PRBC during sepsis

PRBC, packed red blood cells

\section{Results}

Of 32 patients admitted to the ICU during 1992 with the diagnosis of severe sepsis, 31 received PRBCs during their hospital admission and formed the study group. Of these 31 patients (Table II) 19 died, with all deaths occurring during sepsis and in the ICU. Twelve patients survived to be discharged from hospital. Twenty-six patients had positive blood cultures, nine were survivors $(75 \%)$, and 17 were nonsurvivors $(89 \%)$. The criteria for septic shock were met by nine (75\%) survivors and $16(84 \%)$ nonsurvivors. One nonsurvivor was discharged from the ICU only to be readmitted with severe multisystem organ failure from which he did not recover. At no time did this patient meet our criteria for resolution of sepsis so this was judged as a single septic episode. There were no differences between survivors and nonsurvivors with respect to age, sex, days in ICU, duration of sepsis, incidence of septic shock, or APACHE II score, although the latter approached significance $(P=0.06)$.

A total of 555 PRBC units were transfused during hospital admission to the 31 study patients. Ninety seven PRBC units were transfused before the onset of sepsis, 447 during sepsis and 11 units after resolution of sepsis. The latter were too few to analyse. While there was no difference in the total number of units of PRBC transfused to survivors and nonsurvivors (Table III), there was a difference $(P<0.0001)$ with respect to the age of $\mathrm{PRBC}$ units transfused during hospitalisation between survivors (median 21 days) and nonsurvivors (median 24 days, Table III). Further analysis showed that there was no difference between survivors and nonsurvivors in age of PRBC units transfused before the onset of sepsis $(P=0.92)$, but there was a difference in the age of PRBC units transfused during sepsis. When only those PRBC units transfused during sepsis were considered (excluding two survivors who did not receive transfusions while septic), the median age of PRBC units transfused to survivors was 17 days compared with 25 days in nonsurvivors $(P<.0001$, Table III). The association between mortality and the age of PRBC units remained when two patients who received $>90$ units were excluded (median 16 vs 19 days, $P=0.0014$ ). The association was also present, but not statistically significant with Bonferroni's correction, when only those patients (five survivors and four nonsurvivors) who received five or fewer units during sepsis were considered (median 23 vs 29.5 days, $P=.12$ ).

When analysed from a different perspective, the proportion of PRBC units $\leq 16$ days of age transfused during sepsis to survivors was $79 / 163(48 \%)$ ps $75 / 284$ $(26 \%)$ to nonsurvivors (Figure $1, P<0.0001$ ). To examine this difference further, PRBC units given during sepsis were grouped by age and in each age group the proportion of PRBC transfused to survivors and nonsurvivors was determined (Figure 2). Although PRBC of ages 10-20 days were evenly distributed among survivors and nonsurvivors, survivors received a 
greater proportion of $\mathrm{PRBC}<10$ days old (85\%) while nonsurvivors received a greater proportion of $\mathrm{PRBC}$ $>20$ days old $(76 \%)$. Linear regression analysis of the proportion of $\mathrm{PRBC}$ units of a given age transfused to survivors against the age of those units demonstrated a negative correlation $(\mathrm{r}=-.73, P<.0001)$.
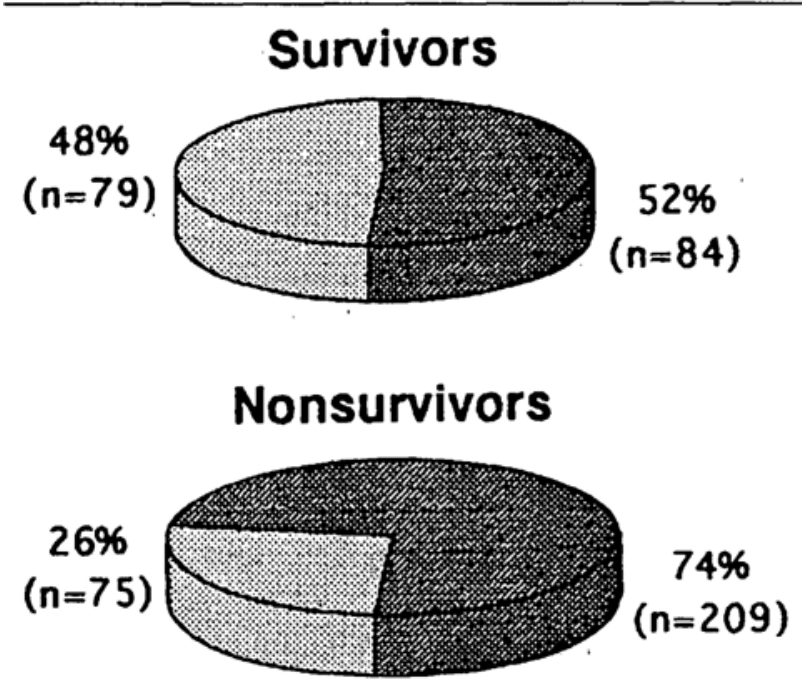

PRBC $\leq 16$ days old

FIGURE 1 Proportion of PRBC units of different age transfused to survivors and nonsurvivors during sepsis

$(P<.0001) . \mathrm{n}=$ number of PRBC units in each subgroup.

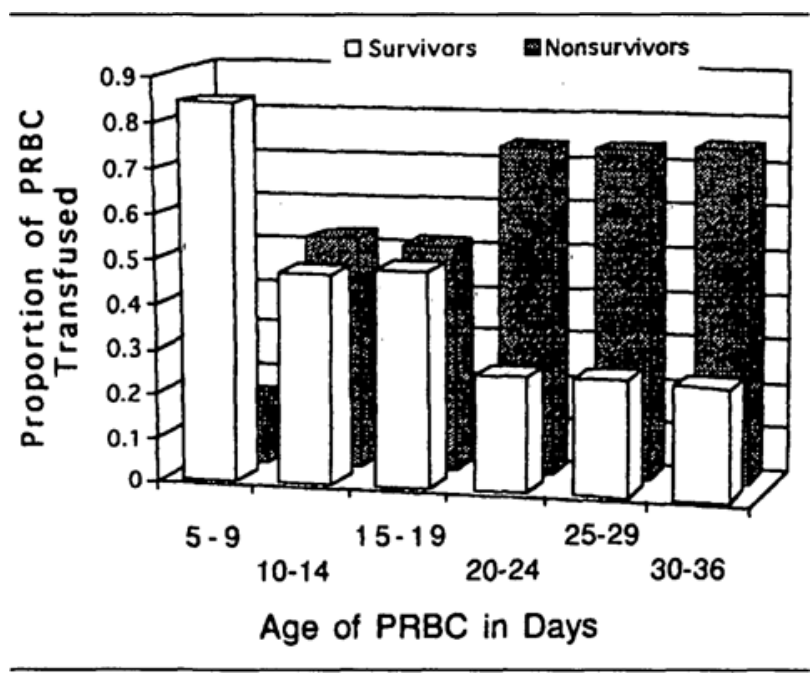

FIGURE 2 Proportion of PRBC units in different age strata transfused during sepsis in survivors and nonsurvivors. Under each age stratum, the summation of the proportions transfused to survivors and nonsurvivors equals one.

\section{Discussion}

This is the first study to report an association between mortality and the age of PRBC units transfused in critically ill patients. While this is an important subject for further investigation, the association cannot be considered proven or causal. Several limitations of this preliminary study must be acknowledged. The study is small and retrospective with neither randomisation nor control over the age of PRBC units transfused. Individual patients often received PRBC units with a wide age range and over a variable time. A few patients received a large number of PRBC units. Despite these limitations, the association of mortality with the age of PRBC units transfused which we have described is compatible with the known changes in PRBC which occur with storage, ${ }^{1}$ and is supported by a recent publication reporting increased mortality in a septic rat model following transfusion with older stored red blood cells. ${ }^{7}$ Further indirect support for possible adverse effects of transfusion of older PRBC is provided by the report that older PRBC units did not improve splanchnic perfusion (as assessed by ultramucosal gastric $\mathrm{pH}$ ) in septic patients, ${ }^{4}$ and that increased ICU length of stay is associated with the transfusion of older PRBC. ${ }^{5}$

Our study provides no information about the possible cause(s) for the association which we have described. However, altered regional and microcirculatory blood flow and oxygen utilisation are believed to be central to the development of organ dysfunction in sepsis. ${ }^{8}$ This may be due in part to sepsis-induced rheologic changes in blood cells. ${ }^{9,10}$ The changes in erythrocytes during storage, many of which are irreversible, have been well documented and include decreased deformability, surface area and fluidity, with increased viscosity and serial enzyme, membrane protein and ion changes. Oxygen affinity is increased due to depletion of 2,3-DPG. ${ }^{1}$ Transfusion of PRBC, while increasing global oxygen delivery during sepsis, may not improve regional blood flow ${ }^{4,11}$ and transfusion older PRBC units may not be associated with increased oxygen uptake. ${ }^{6}$ One plausible hypothesis is that, in the septic patient, the decreased deformability and increased oxygen affinity of transfused older PRBC results in decreased splanchnic blood flow and oxygen utilisation. This may lead to increased gut permeability to bacteria and/or bacterial by-products with a resultant intensification of the septic response.

Another possible explanation for the association reported here is that the number of PRBC units transfused and/or the duration of storage resulted in increased immunosupression. Enhanced kidney graft survival, ${ }^{12}$ increased tumour recurrence $e^{13,14}$ and increased rates of post-operative infection ${ }^{15-19}$ have all been reported following PRBC transfusion. While plasma has been shown 
to have immunomodulatory effects, the primary cellular constituent of PRBC units responsible for immunosupression may be white blood cells. ${ }^{19,20}$ Leucocyte depletion greatly attenuates the immunosupressive effect of PRBC transfusion. ${ }^{19,20}$ The PRBC units in our study were not leucocyte depleted. Increasing mitogenic activity ${ }^{21}$ and histamine release ${ }^{22}$ have both been associated with $\mathrm{PRBC}$ storage time but there is some evidence to suggest that the immunosupressive effect of PRBC may be maxi$\mathrm{mal}$ at two weeks of storage and that PRBC units stored for greater than three weeks may have little immunosupressive effect. ${ }^{23}$ If this is true it suggests that immunosupression was not responsible for the association reported in our study since, on this basis, patients receiving older PRBC units should have been less immunocompromised.

Confounding (and possibly interacting) variables which we could not separate out in this study may account for the association which we have described. For example, the patients that died received a greater number of PRBC units (though this was not statistically significant). This could be either a marker for severity of illness (APACHE II scores also tended to be higher in nonsurvivors) or the larger transfusion load could have had an adverse effect on outcome. Similarly subtle interactions between the severity of illness and length of stay in survivors and nonsurvivors might have resulted in the latter receiving more PRBC units over a longer time period. Because blood bank policy releases older PRBC units first, this could have resulted in nonsurvivors receiving a greater proportion of older PRBC units, and hence the relationship which we have described.

Few general inferences can be drawn from this study which was confined to adult ICU patients admitted with the diagnosis of severe sepsis. Whether other patient groups would show a similar association is unknown. Similarly, no deduction can be made as to what constitutes an acceptable duration of PRBC storage for the septic patient. However, review of studies measuring 2,3-DPG depletion during PRBC storage has led to the recommendation that in patients with compromised circulation PRBC storage for 14 days or less may be preferred. ${ }^{1}$ This recommendation is supported by our findings and by those previously reported. . $^{4}$

The association we have described between mortality and age of PRBC transfusion, if confirmed by a prospective randomised study, would have major implications for blood banking and the use of PRBC in the critically ill septic patient. Further studies are urgently needed to confirm or refute this association and to determine whether or not there are deleterious effects from the transfusion of older PRBC units.

\section{Acknowledgments}

Dr. G. Growe scientific advisor. Dr. S. Naiman, Dr. D. Bevan, Dr. J. Fenwick and Dr. D. Parsons for review of this manuscript. Mrs. P. Lessard and the medical records department of the Vancouver Hospital for their assistance with patient records.

\section{References}

1 Hogman CF. Liquid storage of human erythrocytes. In: Harris JR (Ed.). Blood Separation and Plasma Fractionation. New York: Wiley-Liss, 1991: 63-97.

2 Busund R, Straume B, Revbaug A. Fatal course in severe meningococcemia: clinical predictors and effect of transfusion therapy. Crit Care Med 1993; 21: 1699-705.

3 Chiu P, Roy PD, Marshall JC. Blood transfusion is a risk factor for ICU-acquired infection and the multiple organ dysfunction syndrome (MODS) (Abstract). Crit Care Med 1993; 21: S226.

4 Marik PE, Sibbald WJ. Effect of stored-blood transfusion on oxygen delivery in patients with sepsis. JAMA 1993; 269: 3024-9.

5 Martin CM, Sibbald W, Hebert P, Schweitzer I. Age of transfused red blood cells is associated with ICU length of stay (Abstract). Clin Invest Med 1994; 17: B21, 124.

6 Members of the ACCP/CCM Consensus Conference Committee. American College of Chest Physicians/Society of Critical Care Medicine Consensus Conference: definitions for sepsis and organ failure and guidelines for the use of innovative therapies in sepsis. Crit Care Med 1992; 20: 864-74.

7 Sielenkämper A, Martin CM, d'Almeida M, Sibbald WJ, Chin-Yee I. Transfusion of "old" blood is associated with increased mortality in septic rats (Abstract). Proceedings from the Canadian Society of Transfusion Medicine annual meeting, 1996: 036.

8 Sibbald WJ, Fox G, Martin C. Abnormalities of vascular reactivity in the sepsis syndrome. Chest 1991; 100: S155-9.

9 Machiedo GW, Powell RJ, Rush BF Jr, Swislocki NI, Dikdan $G$. The incidence of decreased red blood cell deformability in sepsis and the association with oxygen free radical damage and multiple-system organ failure. Arch Surg 1989; 124: 1386-9.

10 Astiz ME, DeGent GE, Lin RY, Rackow EC. Microvascular function and rheologic changes in hyperdynamic sepsis. Crit Care Med 1995; 23: 265-71.

11 Lorente JA, Landin L, De Pablo R, Renes E, Rodrigue $Z$-Diaz $R$, Liste $D$. Effects of blood transfusion on oxygen transport variables in severe sepsis. Crit Care Med 1993; 21: 1312-8.

12 Rodey GE. Blood transfusions and their influence on renal allograft survival. Prog Hematol 1986; 14: 99-122. 
13 Clarke PJ, Tarin D. Effect of pre-operative blood transfusion on tumour metastases. Br J Surg 1987; 74: 520-2.

14 Chung M, Steinmetz OK, Gordon PH. Perioperative blood transfusion and outcome after resection for colorectal carcinoma. Br J Surg 1993; 80: 427-32.

15 Jensen LS, Andersen AJ, Christiansen PM, et al. Postoperative infection and natural killer cell function following blood transfusion in patients undergoing elective colorectal surgery. Br J Surg 1992; 79: 513-6.

16 Tartter PI. Blood transfusion and infectious complications following colorectal cancer surgery. Br J Surg 1988; 75: 789-92.

17 Mibolic J, Hudec M, Domanig E, et al. Risk factors for severe bacterial infections after valve replacement and aortocoronary bypass operations: analysis of 246 cases by logistic regression. Ann Thorac Surg 1985; 40: 224-8.

18 Triulzi DJ, Vanek K, Ryan DH, Blumberg N. A clinical and immunologic study of blood transfusion and postoperative bacterial infection in spinal surgery. Transfusion 1992; 32: 517-24.

19 Jensen LS, Kissmeyer-Nielsen P, Wolff B, Qvist N. Randomised comparison of leucocyte-depleted versus buffy-coat-poor blood transfusion and complications after colorectal surgery. Lancet 1996; 348: 841-5.

20 Blumberg N, Heal JM. Effects of transfusion on immune function. Cancer recurrence and infection. Arch Path Lab Med 1994; 118 : 371-9.

21 Hob H, Umpleby H, Cooper A, Taylor I. Recurrence of colorectal cancer and perioperative blood transfusion. Is blood storage time important? Dis Colon Rectum 1990; 33: 127-30.

22 Nielsen HJ, Edvardsen L, Vangsgaard K, Dybkjor E, Skov PS. Time-dependent histamine release from stored human blood products. Br J Surg 1996; 83: 259-62.

23 Mincheff MS, Meryman HT. Blood transfusion, blood storage and immunomodulation. Immunological Investigations $1995 ; 24$ : 303-9. 